\begin{tabular}{|c|c|c|c|}
\hline Article Info & RESEARCH ARTICLE & ARAŞTIRMA MAKALESİ & \\
\hline Title of Article & \multicolumn{2}{|c|}{$\begin{array}{l}\text { The Relationship between Biophilic Design } \\
\text { and Spatial Justice in Cities: The } \\
\text { Experience of Neighborhood Parks }\end{array}$} & 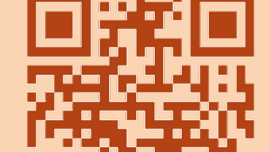 \\
\hline $\begin{array}{l}\text { Corresponding } \\
\text { Author }\end{array}$ & \multicolumn{2}{|c|}{$\begin{array}{l}\text { Sevim Pelin ÖZTÜRK } \\
\text { İzmir Demokrasi Üniversitesi, Mimarlık Fakültesi, Şehir ve Bölge Planlama Bölümü, } \\
\text { sevimpelin.ozkan@idü.edu.tr }\end{array}$} & \\
\hline $\begin{array}{l}\text { Received Date } \\
\text { Accepted Date }\end{array}$ & \multicolumn{2}{|c|}{$\begin{array}{l}03.07 .2021 \\
14.09 .2021\end{array}$} & \\
\hline DOI Number & \multicolumn{2}{|l|}{ https://doi.org/0.35674/kent.961865 } & \\
\hline Author / Authors & Sevim Pelin ÖZTÜRK & ORCID: 0000-0002-1698-0344 & \\
\hline How to Cite & \multicolumn{2}{|c|}{$\begin{array}{l}\text { Öztürk, S.P. (2021). Kentlerde Biyofilik Tasarım ve Mekansal Adalet İlişkisi: Mahalle } \\
\text { Parkları Deneyimi, Kent Akademisi, Volume, } 14 \text { Issue 3, Pages, 533-544. }\end{array}$} & $\begin{array}{l}\text { Kent Akademisi } \\
\text { Urban Academy }\end{array}$ \\
\hline
\end{tabular}

\title{
Kentlerde Biyofilik Tasarım ve Mekansal Adalet İlişkisi: Mahalle Parkları Deneyimi
}

\begin{abstract}
:
Biophilic design as a planning approach emphasizes nature and the natural environment in urban planning and is called as 'naturalization of urbanization'. Biophilic approaches to urban planning aim to increase the percentage of natural or artificial open-green spaces in the urban fabric, and to maximize the accessibility of and beneficial experience in these areas. The main argument of the study is to focus on micro-scale spatial interventions and solutions starting from the local scale instead of macro and upper scale transformation and interventions in cities. It is acknowledge that the interventions at local spatial levels may increase the integration and connection with upper levels in cities. The study focuses on neighborhood scale, measuring the accessibility of neighborhood parks and searching for park linking networks using a point-based accessibility approach. The operationalization of the analytical spatial approach has been designed in the model of data-based design. A GIS database is created using spatial data of existing urban environment, using ArMap 10.5 and network analysis as a GIS software. The accessibility of existing parks in the study area is calculated using network (actual distance) based service area analysis. Access lines via streets within a maximum of $500 \mathrm{~m}$ walking distance to parks are calculated that is revealing what is the walking distance between residences and closest parks. As a result of the analysis, it is seen that the existing parks are accessible within 300m on average. However, it is observed that some residential units could not access any park area within 500m walking distance. New parks are proposed in existing urban voids to increase accessibility to parks. Therefore, 9 new park areas are proposed to increase accessibility and pedestrian-oriented routes are proposed to revive the Meles river as a connecting natural element. By means of new routes and parks, the green space integration and the sense of spatial justice will be both strengthened.
\end{abstract}

KEYWORDS: Biophilic Urbanism, Neighborhood Parks, Accessibility.

${ }^{1}$ İzmir Democracy University, Faculty of Architecture, Department of City and Regional Planning, sevimpelin.ozkan@idü.edu.tr Kentlerde Biyofilik Tasarım ve Mekansal Adalet İlişkisi: Mahalle Parkları Deneyimi Journal of Urban Academy | Volume: 14 Issue:3 | ISSN: 2146-9229

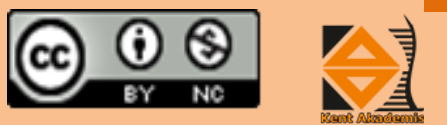




\section{ÖZ:}

Günümüzde kentsel planlamada doğa ve doğal çevreyi öne çıkaran ve kentleşmenin doğallaştırılması olarak gündeme gelen yaklaşım biyofilik tasarım ve planlama yaklaşımıdır. Biyofilik yaklaşımlar, doğal veya yapay açık-yeşil alan, doku ve parçaların kentsel doku içerisindeki yüzdesinin artırılması ve ayrıca bireylerin bu alanlara erişiminin ve alan deneyimlerinin en yüksek seviyeye çıkartılmasını amaçlamaktadır. Bu çalışmanın ana argümanı, kent bütünde makro ve üst ölçek planlama ve dönüşüm müdahaleleri yerine mikro-müdahaleler ile yerel ölçekten başlayan çözümlerin keşfedilerek ön plana çıkartılmasıdır. Yerelde yapılan müdahaleler ile kent bütününde entegrasyonun artacağı ve ulaşım bağlantılarının kuvvetleneceği öngörülmektedir. Yerel ölçek olarak mahalle ve konut çevresi ölçeğine odaklanan çalışma, mahalle parklarının erişilebilirliği ve olası park bağlayıcı ağların keşfini nokta tabanlı erişilebilirlik yaklaşımı ile ele almıştır. $\mathrm{Bu}$ analitik mekansal yaklaşımın operasyonel hale gelmesi veri temelli model tasarımı şeklinde kurgulanmıştır. Mevcut mekansal veriler kullanılarak CBS veritabanı oluşturulmuş, CBS yazılımı olarak ArcMap 10.5 ve network ağ analizleri kullanılmışıı. Çalışma alanında bulunan mevcut park alanlarının erişilebilirliği, network (gerçek mesafe) tabanlı çalışan servis analizi kullanılarak hesaplanmıştır. Park alanlarının maksimum $500 \mathrm{~m}$ içindeki erişim hatları hesaplanmıştır ve böylece alandaki konut birimlerinin (en kısa) hangi mesafede bir park alanına eriştiği ortaya konulmuştur. Yapılan analizler sonucunda, mevcut parkların ortalama $300 \mathrm{~m}$ içerisinde erişim sağlandığ görülmüş̧ür. Fakat bazı konut birimlerinin 500m içerisinde bir park alanına erişemediği tespit edilmiş, bu nedenle park alanlarına erişimi arttırmak için mevcut yapılaşmamış alanlarda yeni park alanları ile birlikte Meles deresini bağdaştırıcı bir unsur olarak canlandırmak için yaya odaklı akslar önerilmiştir. Bunlar, park alanlarını ve su öğesini kapsayan yaya öncelikli akslar olarak nitelendirilebilir. Bu sayede hem yeşil alan entegrasyonu iyileştirilmiş hem de mekansal adalet duygusu kuvvetlendirilmiştir.

ANAHTAR KELIMELER: Biyofilik Kentleşme, Mahalle Parkları, Erişilebilirlik .

\section{GİRIŞ:}

Kentlerin sunduğu yaşam kalitesinin artırılması için tarih boyunca doğayı ve doğal unsurları mekezine alan birçok planlama yaklaşımı geliştirilmiştir. 19. yy sanayi kentlerindeki olumsuz yaşam koşullarına bir eleştiri olarak ortaya atılan 'bahçe kent' yaklaşımı, günümüzde biyofilik tasarım anlayışıyla 'bahçe içinde kent' yaklaşımıyla tekrar hayat bulmuştur. Biyofilik yaklaşım ile mekan tasarımının bir araya gelmesi ve mimari uygulamalar ile kentsel tasarım ve planlamada yer bulması son 10 yılda oldukça hız kazanmıştır. Birçok kent, mekânsal politikalarında ve stratejilerinde biyofilik program, politika ve inisiyatif geliştirmeye ve uygulamaya başlamıştır. Bu programların amacı kentsel alanlarda ve mimari ölçeklerde biyofilik prensipleri uygulamaktır. Singapur en çok bilinen biyofilik şehirlerin başında gelmektedir (Matan ve Newman, 2015). Biyofilik kent politikası ile, bölge planlamadan kentsel tasarıma ve yap1 ölçeğinde mimari tasarıma kadar birçok farklı mekansal ölçekte biyofilik tasarım örnekleri sunan mekan kurguları oluşturmuşlardır.

Biyofilik tasarım, farklı mekansal ölçeklerde doğa esaslı uygulamaya yönelik çözümler önermektedir. Doğa esaslı çözümler, kentsel yoğun dokuların 'doğallaştırılması', bozulmuş alanların doğal öğelerle iyileştirilmesi, yeşil altyapılar, su yönetimi ve teknik olmayan uygulamaları da içerir. Yeşil koridorlar, sulak alanlar, kent ormanları, akarsu ve dereler, hobi bahçeleri ve kentsel tarım alanları, mahalle parkları ve mini parklar, suyun akıllı kullanımı sağlayan ve sel/taşkın etkilerini azaltan drenaj sistemleri, yeşil duvarlar, dikey bahçeler, yeşil çatılar ve avlular, iç mekan bitkilendirmesi uygulama örneklerinden bazılarıdır. Ayrıca farklı ölçeklerdeki bu uygulamalarda, ahşap-beton gibi doğal mimari elemanlar ve kentsel alanlarda geçirgenliği yüksek malzemeler kullanılmaktadır. Bunların yanı sıra teknik olmayan müdahaleler de biyofilik yaklaşımın bir parçasıdır. Bu müdahaleler; iklim duyarlılık eğitim programları ve pratik uygulama alanları ve halkın eğitim faaliyetlerine katılımının sağlanması, halkın birlikte-tasarım faaliyetlerine katılımının desteklenmesidir. Doğa esaslı çözümlerden beklenen etkiler; mikro ölçekte kentsel sıcaklığı düşürmesi, 1S1 adası etkisini azaltması, sel-taşkın riskini önlemesi, yoğun kentsel trafik kaynaklı hava kirliliğini azaltması ve suyun verimli kullanılması, makro ölçekte ise karbon salınımını azaltması ve toprak verimini yükseltmesidir (Özden, 2019).

Kentsel planlamada biyofilik yaklaşımlar, doğal veya yapay açık-yeşil alan, doku ve parçaların kentsel doku içerisindeki yüzdesinin arttırılması ve beraberinde bireylerin bu alanlara erişiminin ve alan deneyimlerinin en yüksek seviyeye çıartılmasını amaçlamaktadır. Wilson (1984) tarafından önerilen 'biyofili' kavramı, sürdürülebilirlik anlayışı ile 
kentsel planlamaya yeni bir bakış açısı getirmiştir (Özden, 2019). Sürdürülebilirlik ve iklim değiş̧ikliğine dirençli kentleşme yaklaşımlarından da beslenen Biyofilik yaklaşım, farklı mekânsal ölçeklerde doğa esaslı çözümler sunmayı hedefler. Biyofilik tasarım; kent, bölge, mahalle, sokak ve bina ölçeğinde iyi tasarımın doğayı ve doğal unsurları içermesi gerektiğini belirtir (Beatley ve Newman, 2013). Biyofilik yaklaşım, kentsel bölgeden bina/yapı ölçeğine kadar uygulamaya yönelik çeşitlilik sunarak farklı mekansal ölçeklere değinmektedir. Bu çözümleri sunarken de, bireysel mekân deneyiminin sağlanmasını temel kaygı ve amaç olarak ortaya koyar. Biyofilik mekân tasarımı ile öne çıan kentlerde ölçek çeşitliliği, milli/ulusal parklardan, mini parklara ve yeşil yapı çözümlerine kadar farklı düzeylerde görülmektedir.

Farklı ölçeklerdeki farklı biyofilik uygulamalar; nitelik, biçim ve ölçek çeşitliliklerinin yanı sıra, doğası gereği hem mülkiyet biçimi hem de erişilebilirlikleri bakımından da çeşitlilik göstermektedir. Kentsel planlama yaklaşımları sadece fiziksel çevreyi değil, kamusal kaynakları dağıtması özelliği ile de mekânsal adaleti şekillendirmektedir. Kentsel planlamada biyofilik yaklaşımın, önerdiği mekansal çözümlerin mülkiyet desen dağılımı kentsel alandaki kamusal ve özel açık-yeşil alanların oranını etkilemesi ile mekânsal adaleti şekillendiren bir boyutu da bulunmaktadır. Mekansal adalet kavramı birçok mekansal ve mekansal olmayan dinamiği kapsamaktadır. Kentsel mekansal adaleti, kamusal kaynakların kent sakinleri arasında dağıtımıyla ve farklı bireysel özelliklerdeki kent sakinlerinin bu kaynaklara erişilebilirlik ile ilişkilendiren birçok bilimsel çalışma bulunmaktadır (Talen ve Anselin, 1998; Tan ve Samsudin, 2017) Bu bağlamda mekansal adalet, kent sakinlerinin yaşam kalitelerinin ve kamusal hizmetlere erişimlerinin yakın oranlarda olması ile sağlanabilir. Kentsel kamusal kaynaklardan olan açık yeşil alanların biyofilik yaklaşımın odak konusu olduğu söylenebilir. Kamusal niteliği bulunan açık yeşil alanların bu yönüyle mekansal adalet çerçevesi içinde de büyük bir yeri vardır (Talen ve Anselin, 1998). Biyofilik yaklaşımın sunduğu doğa esaslı yaklaşım; yapı ölçeğinde özel mülkiyete tabi çözümler üretirken, bir yanda da erişimi ve deneyimlenebilirliği yüksek kamusal alanlardan oluşan çözümler üretmesi, kentlerdeki mekânsal adaleti de güçlendirir. Kent ve mahalle ölçeğinde kullanıcılara ulaşılabilir açık yeşil alan alternatifleri sunulması hem sosyal değer katması hem de kullanıcıların yaşam standartlarının artırması açısından önemli getirileri olmaktadır.

Kent ve bölge ölçeğinde ilişkisel bir yeşil sistemler bütünü olması önerilen biyofilik tasarımın, kamusal niteliği en yüksek parçaları mahalle ölçeğindeki açık ve yeşil alanlardır. Yürüyerek erişilebilir ve farklı bireyler tarafından deneyimlenebilir açık ve yeşil alanların mahalle ölçeğinde planlanması gerekmektedir. Mahalle ölçeğinde planlanan mahalle parkları ve mini parklar, konut alanlarına 5-10 dakika yürüme mesafesinde olmalıdır. Bu parklar, önemli bir kamu hizmeti alanı olan kamusal yeşil alanlardır. Kentsel yeşil alanlar, bireylerin refahı, kentsel çevre kalitesi, hava kalitesi, sosyal bütünleşme ve mekânsal adalet için de önemlidir (Ekkel ve de Vries, 2017; Kara vd., 2011; Swyngedouw ve Heynen, 2003; Williams, 2002). Ancak günlük hayatta bireylerin mahalle parklarına erişimi, mahalleler arasında ve konut alanları arasında farklılık gösterebilmektedir. Mahalle parklarının konumu, bireylerin yürüyerek erişimini şekillendiren en önemli faktörlerdendir. Bireylerin yürüme kapasitelerindeki farklılıklardan dolayı (Stafford ve Baldwin, 2018), parklar için konum seçimleri, birçok fiziksel ve coğrafi özellik (mesafe, eğim, akarsu yolları, sokak ağı, trafik yoğunluğu ve arazi kullanımı gibi) dikkate alınarak belirlenmelidir. Bu çalışma kapsamında, gerçek bir konut alanında, mevcut doğal ve yapılı çevre etmenleri dikkate alınarak, erişimi yüksek mini park alanları yer seçim önerisi ve yeşil alanlar arasında bağlayıcı rol üstlenecek yaya odaklı koridor önerileri gerçekleştirilecektir.

\section{Parklar, Erişilebilirlik ve Biyofilik Kent}

Biyofilik tasarım anlayışı, kent bütünündeki mevcut doğal öğelerin görünürlüğünü arttırarak ve yapay doğal öğelerle buluşturarak yeşil bir altyapı sistemi kurmayı hedefler. Kent bütününde üretilen yeşil sistemin birçok alt parçası vardır. $\mathrm{Bu}$ sistem açık-yarı açık ve kapalı alanlardan ve bağlayıcı koridorlardan oluşmaktadır. Alanlar, tematik park ve bahçelerden, tarım alanlarından, mini parklardan ve doğal malzeme ve öğelerle (yeşil çatı, kış bahçesi, dikey bahçe vb.) donatılmış yarı açık ve kapalı alanlardan oluşmaktadır. 'Park Bağlayıcı Ağ (Park Connector Network)' olarak adlandırılan koridorlar, bu yeşil alanları birbirine bağlayan yaya ve bisiklet odaklı ulaşım hatlarıdır (Matan ve Newman, 2015; Newman, 2014). Park Bağlayıcı Ağlar, kent bütünündeki başlıca yeşil alanları ve belirli varış noktalarını (özellikle yerleşim yerlerini) birbirine bağlayan, doğrusal bir park ağı olarak tasarlanır. Bu bağlayıcı ağlar ile entegre bir yeşil ekosistem kurulması ve bu yeşil sistemin sürdürülebilir olması esas alınır.

Biyofilik kent yaklaşımının uygulanacağı planlama müdahalesinde amaç, kentsel gelişmenin engellediği yerlerde doğal alanları yeniden canlandırmak, biyoçeşitlilik araştırmaları yoluyla yerli flora ve fauna hakkında bilgi sağlamak, yeni 
parklar ve park bağlayıcı ağlar oluşturarak doğayı korumaktır. Parklar ve park bağlayıcı ağlar ile yeşil ekosistem oluşturmanın ana hedefi, biyoçeşitliliği iyileştirmek, kentsel ısı adası etkisini azaltmak, dış mekânın termal konforunu arttırmak, yağmur suyu sistemleri ile su yönetimini sağlamak ve yapılarda enerji tüketimini azaltmaya yardımcı olmaktır. Kentsel planlamada biyofilik müdahaleler üç temel kategoride geliştirilmiştir: Mekândaki doğa (nature in the space), doğa analojileri (nature analogues) ve mekânın doğası (nature of the space). Mekandaki Doğa, doğanın farklı form ve biçimleri (bitkiler, su, hayvanlar) olduğu kadar esintiler, sesler ve kokular gibi doğayı deneyimlemenin doğrudan ve dolaylı yollarını dikkate alır. Mekanda doğa deneyimleri, "özellikle çeşitlilik, hareket ve çok-duyusal etkileşimler yoluyla bu doğal unsurlarla anlamlı, doğrudan bağlantılar" kurma yoluyla geliştirilir. Doğa analojileri, doğada görülen desenlerin, renklerin, şekillerin, dokuların ve malzemelerin çoğaltılmasını ifade eder; duvarlarda yaprak veya kabuk motifleri, mobilyalarda ahşap ve granit kullanımı ve doğada yaygın olarak görülen geometrik desenlerin kullanımını içerebilir. Mekânın doğası, yakın çevrenin ötesindeki bulunan doğal alanlara ve deneyimlere erişim (beklenti) ve çevresel koşulların kullanıcılara hissetirdiği duygular üzerinde durur. Kullanıcılarda merak, güven, huzur gibi duyguları harekete geçirmeyi hedefler (Reeve vd., 2015).

$\mathrm{Bu}$ üç temel biyofilik mekansal müdahale, şehirlerde zaten var olan doğanın tekrar tanınmasını, korunmasını, geliştirilmesini ve aynı zamanda yeni doğa biçimlerinin (mekanlarının) tasarımını ve entegrasyonunu önceller. Biyofilik kentleşme için temel kaygı, doğayı stratejik olarak yapılı çevreye sokarak, olumlu psikolojik ve fizyolojik tepkileri teşvik edebilecek kentsel ve mimari alanlar oluşturmak, bu alanların kullanıcılarına da doğa deneyimleri sağlamaktır. Biyofilik kentler literatüründe Singapur modeli önemli yer tutmaktadır ve birçok kente örnek model ve yaklaşım sunmaktadır. Singapur'un bunu oldukça hızlı bir şekilde başarması, kent planlama alanında yenilikçiliğe olan bağlılıklarını da göstermektedir. Singapur biyofilik şehircilik örneği, planlama mevzuatındaki düzenlemeleri ve yenilikçi planlama politikaları, katılımcı ve şeffaf tasarım süreçleri ile ana akım kentleşme literatüründe yer bulacağını göstermiştir. Biyofilik şehirciliğin gelişimindeki bir sonraki aşama, çok farklı iklim koşullarına sahip kentlerin benzer ilkeleri uygulaması ve gelişmiş şehirlerin biyoçeşitlilik, estetik nitelikler, enerji, su, sağlık, toplumsal kabul ve ekonomik açılardan edinilen kazanımları değerlendirerek ve sayısallaştırarak süreci ana akım haline getirmesi olacaktır. (Newman, 2014).

$\mathrm{Bu}$ çalışma, kentlerdeki biyofilik tasarım yaklaşımıyla da perçinlenen yeşil altyapı sistemlerinin en temel öğesi olan, mahalle ölçeğindeki yeşil sisteme ve bu sistemin parçalarından mahalle parklarının mekânsal dağılımına odaklanacaktır. Parkların mahalle ölçeğinde mekansal dağılımını incelerken, mevcut doğal ve yapay etmenleri göz önüne alarak, erişilebilirliği yüksek ve mekansal adalet hissi güçlü bir dağılım önerisi sunmayı hedeflemektedir. Mahalleler genellikle konut alanlarının yanısıra, gündelik hayatı destekleyen diğer arazi kullanımlarını da barındırması beklenen yerleşim alanlarıdır (Moser vd., 2002). Buna göre mahalle, kişinin konutundan 5-10 dakikalık yürüme mesafesinde (en çok $800 \mathrm{~m}$ içinde), kamusal hizmet alanlarına ve diğer hizmet alanlarına erişebildiği yerleşim alanı olmalıdır (Kearns ve Parkinson, 2001; Moser vd., 2002). Bu kamusal alanlardan en önemlileri, kentsel çevrenin ve bireylerin sağlıklarına önemli katkılar sunan mahalle parklarıdır. Mahalle parkları, kişinin psikolojik-sosyal refahını ve sosyalleşme, rahatlama, güvenlik ve aidiyet duygusunu geliştirdikleri için günlük rutinlerini desteklemesi beklenir (Day, 2008). Bunun yanısıra, kentsel ekosistemin ve yeşil altyapının temel alt parçalarından birisidir.

Mahalle parklarının konum tahsisi ve erişilebilirliklerinin tespiti ve değerlendirilmesi için farklı operasyonel yaklaşımlar geliştirilmiş̧ir (Apparicio vd., 2008; Talen ve Anselin, 1998). Bunlar, yer (alan) tabanlı ve nokta tabanlı yaklaşımlar olmak üzere iki ana gruptadır (Kwan, 1999; Neutens vd., 2010). Yer temelli yaklaşım, erişilebilirliği belirli bir mekansal birime düşen kamu hizmet alan büyüklüğüne ve kişi başına düşen alan büyüklüğüne göre değerlendirmektedir (Rigolon, 2016; Tan ve Samsudin, 2017). Yeşil alanlar söz konusu olduğunda, bu yaklaşım, kişi başına yeterli büyüklükte yeşil alana sahip bir mahallenin sakinlerinin bu yeşil alanlara erişimi olduğunu ve dolayısıyla bu alanlardan yarar sağlayabildiğini varsayar. Ülkemizde mekansal plan yapım süreçlerinde genellikle bu yaklaşım kullanılır ve 3194 Sayılı İmar Kanununun belirlediği kişi başına düşen yeşil alan standardı, her mahalle sınırı içindeki yeşil alanların toplam büyüklüğü ile mahallenin toplam nüfus sayısı arasındaki oranla kıyaslanarak erişilebilirlik hesaplanır. Fakat bu yaklaşım, birçok mekansal dışsallıkları ve coğrafi konum özelliklerini göz ardı eder. Bu yanıyla yer tabanlı erişim modelleri, kentsel yeşil altyapı sistemlerinin inşasında ve sistemin değerlendirilmesinde kullanmak için birçok kısıt taşımaktadır.

Öte yandan, nokta tabanlı yaklaşım, erişilebilirliğinin ölçülmesi için daha fazla sayıda ve karmaşık değişkeni içerebilen mekânsal modellemeler yapabilmektedir (Kwan, 2010; Neutens vd., 2010; Tsou vd., 2005). Bu yaklaşım, yarıçap 
analizi, en kısa mesafe analizi, kütle-çekim modeli ve (birey odaklı erişim ölçümlerinde) 3 boyutlu zaman-mekân prizma modeli gibi yöntem ve teknikleri içermektedir. Alan tabanlı yaklaşımdan temel farkı, erişimi ölçülen alanın bir coğrafi nokta olarak ele alınması ve bu alanın ne kadar mesafeye veya alana hizmet verebildiğinin ölçülmesidir. En önemli avantajı ise, gerçek mesafe ile ölçüm yapabilmesidir. Cadde ağı ile coğrafi mesafeyi yansıtmanın yanı sıra, bu yaklaşıma sahip modeller, hizmet alanlarının miktarını ve ölçeğini, hizmet verilecek insan sayısını ve farklı gruplar tarafından yürünebilirliğin fiziksel ve doğal eşiklerini veya engellerini de modellemektedir (Barton ve Grant, 2010; Tan ve Samsudin, 2017).

Nokta tabanlı yaklaşımın en gelişmiş hali birey odaklı erişim yapmaya olanak sunan 3 boyutlu zaman-mekan modelleme teknikleri. Birey odaklı mekan-zaman ölçüm yöntemi; bireysel aktivite alanı ve süresinin ve yine bireylerin aktivite alanında karşılaştı̆̆ caydırıcı ve firsat faktörlerinin modellenmesi ile bireysel erişimi ölçmektedir (Kwan, 1999; Neutens vd., 2010). Mekan-zaman ölçüm tekniklerinden, biri 3 boyutlu mekan-zaman prizması (diğer adıyla olası rota mekanı) ve erişimi ölçülen alanın sunduğu fiziksel özellikleri hesaba katarak, farklı bireyler için mekanın farklılaşan çekiciliğini ölçen yöntemlerdir (Kwan, 2010). Mekan-zaman ölçüm yöntemleri, olası 3 boyutlu rota mekanını, bu mekanın sunduğu fırsat, faydalar ve caydırıcı faktörler ile birlikte ele alır.

Birey odaklı ölçüm yöntemleri, ağ-mesafe tabanlı çalıştığı gibi bireysel farklılık gösteren aktivite programına da tabii kalarak hesaplamalar yapar. Bireysel yolculuk tutumları ve bunların mekan-zamanı, farklı cinsiyet, ırk ve yaş gruplarında farklılık göstermektedir (Neutens vd., 2010). Üç temel mekan-zaman ölçüm yöntemi belirtilmiştir. Bunlar, olası rota mekânı üzerindeki firsatların sayısı, olası rota mekânı üzerindeki firsatların ağırlıklı toplamı ve olası rota mekânının ağ-mesafe uzunluğu ölçümlerine dayanmaktadır. Bu yöntemleri uygulayabilmek için detaylı günlük yolculuk program bilgisi, yolculuk zamanı ve maliyeti bilgisi, yol ağı verisi ve kentsel aktivite veya hizmet alanlarının sabit konum verisine ihtiyaç vardır. Birey odaklı ölçüm yöntemleri kapsamında, birçok çalışmada coğrafi bilgi sistemleri (CBS) araçlarından yararlanılmıştır (Kwan, 1999, 2002, 2010). Bu çalışmalar özellikle cinsiyet ve yaş grubu odaklı araştırmalardır. CBS tabanlı mekan-zaman prizma yöntemi, özellikle kadınların gündelik yaşamlarını ve belirli kamusal hizmetlere olan erişimlerini betimleyici model oluşturarak hesaplayan çalışmalarda kullanılmıştır.

Bu çalışmada, biyofilik yaklaşımın çözüm önerilerinde olan kentsel yeşil bir altyapının planlanmasında ve mekansal adaleti sağlamada önemli rolleri olan mahalle parklarının erişilebilirliğinin ve park bağlayıcı ağların, coğrafi bilgi sistemleri kullanarak modellenmesi gerçekleştirilecektir. İzmir kentinde, bir ekolojik omurgaya dönüştürme politika ve çabaları olan Meles Deresinin sahip olduğu potansiyel göz önüne alınarak, Meles Deresi üzerinde Şehitlik Korusunun kuzeyindeki yoğun bir konut alanı çalışma alanı olarak seçilmiştir. Bu konut alanında mevcut ve öneri parklar ve parklar arası erişilebilirliği modellemek için nokta tabanlı mekansal yaklaşım uygulanacaktır. Mahalle gibi alt ölçeklerde gerçek mesafe dikkate alınarak yapılacak analiz, aynı mahallede yaşayanlar için dahi farklı erişim fırsatlarının olduğunu göstererek, mekânsal eşitsizlikleri gün yüzüne çıkarmayı hedeflemektedir (Tan ve Samsudin, 2017; Tsou vd., 2005). Yine bu çalışma kapsamında, bir örnek alan çalışması sunularak, biyofilik kent planlama çalışmalarına, erişilebilirliği yüksek ve mekansal adaleti güçlü bir kent modeli önerisi yapılarak katkı sunulması hedeflenmektedir.

\section{1. Çalışma Alanı}

Çalışma alanı, İzmir kenti kuzey aksında uzanan ve Alsancak Limanında delta alanı oluşturan Meles Deresi üzerindeki Şehitlik Korusunun güneyinde bulunan konut bölgesidir. İzmir kentinde çok az sayıda olan Kültürpark, Şehitler Korusu gibi büyük yeşil alanlar, çevredeki büyük yeşil alanlar ve sahil bandına doğru bağlantı sağlayarak sürekliliği tamamlayan önemli bileşenlerdir (İzmir Büyükşehir Belediyesi, 2021). Çalışma alanın bir kısmı Buca ilçesinde bulunurken, diğer kısmı Karabağlar ilçesinde konumlanmaktadır çalışma alanı yaklaşı 140 hektar olup 5 farklı mahalle sınırına da girmektedir. Bu mahallelerden Osman Aksüner, Aşıkveysel, Cennetoğlu, Akıncılar Karabağlar ilçesinde, Seyhan ve İnkılap Buca ilçesinde yer almaktadır. Çalışma alanı sınırı ise, Meles Deresinden 500m yürüme mesafesi içerisinde bulunan parkları kapsayacak biçimde bir alan olarak belirlenmiştir. Bu bölge, konut kullanımının görece fazla olması ve yürüyerek erişimi kısıtlayacak öğelerin (tren hattı, geniş karayolu, riskli alan) yine görece az olması sebebiyle seçilmiştir (Şekil 1). Mevcut ulaşım altyapısı ve yapılaşma biçimi, kullanıcı-yeşil sistem-su ilişkisini kesintiye uğratmaktadır. Mevcut doku ve Meles Deresi arasındaki mekansal ilişki erişim açısından sorunlu olsa da, Meles Deresi bir su öğesi olarak ve de kent içindeki izlediği rota ile İzmir kentinin ekolojik omurgası olma potansiyeline sahiptir. Biyofilik tasarım ve planlama bağlamında, böyle bir potansiyelin kullanılması önemli ve önceliklidir. Bu yaklaşım bağlamında, suyun izlediği rotaya saygı duyulmalı ve mekân suyun doğal akışıyla şekillenmelidir. 


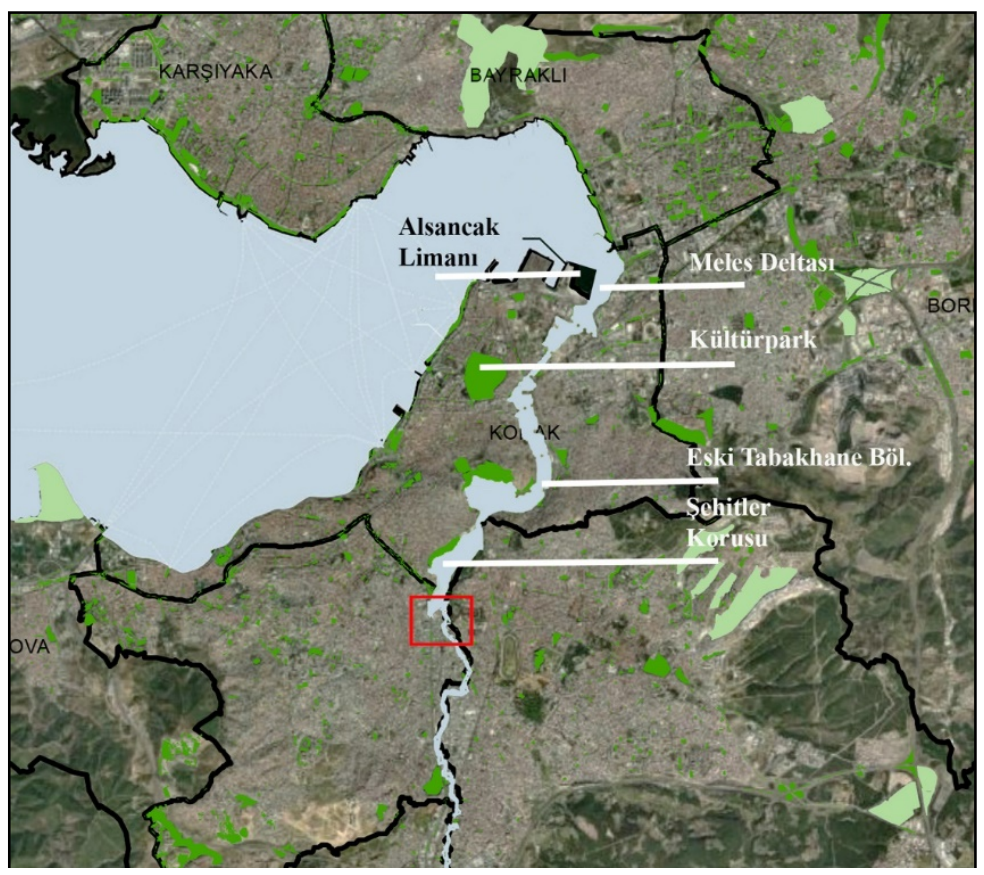

Şekil 1: Meles Deresi ve Çalışma Alanı (İzmir Büyükşehir Belediyesi, 2021)

2021 y1lında yaklaşık 4,5 milyon kişi nüfus büyüklüğüne ulaşan İzmir, Türkiye'nin en kalabalık şehirlerinden birdir. Toplam 30 ilçesinden 9'u merkez ilçelerdir ve göreceli olarak yüksek nüfus yoğunluğuna sahiptir (Türkiye İstatistik Kurumu, 2020). İzmir kenti, merkez ilçelerinin görece yüksek nüfusu, giderek artan kentsel alanı ve kentsel saçaklanmanın getirdiği sorunlarla başa çıkmak için biyofilik tasarım ve yeniden-doğallaştırma stratejilerini uygulama odaklı çalışmalar yapmaktadır. Bu bağlamda İzmir kenti Avrupa Birliği projesi 'Urban Greenup'ın bir parçasıdır. 2017 yılında başlayan projede beşi Avrupa'da olmak üzere sekiz farklı şehir partneri vardır. İzmir kenti, doğa esaslı çözümlerin uygulanacağı ve diğer kentlere yol gösterici olacak üç öncü kent arasında bulunmaktadır. Bu projenin, birçok yönüyle kent ölçeğinde biyofilik tasarımın uygulamaya dönük yöntemlerini araştırdığı görülmektedir. İzmir'in yaşadığı kentsel sorunları doğa odaklı çözümler sunarak aşmayı hedeflemektedir. Uygulanacak çözümler genel olarak yeşil koridor oluşturma ve kentteki ısı adası etkisinin azaltılması üzerine odaklanacaktır. Daha özelde ise uygulanacak çözümler dört ana kategoride gruplandırılmıştır (European Union's Horizon 2020 Research and Innovation Programme, 2021):

a.Kentleşmenin yeniden doğallaştırılması

Yeşil koridor üzerinde yaya ve bisiklet yolları

Ağaçlık bölgeler ve parklar oluşturulması ve ağaçlandırma yapılması

Kentsel koruluklar yoluyla karbon yutak alanları oluşturulması

b.Su çözümleri

Suyun depolanması ve filtrelenmesi için saklama havuzları ve doğal yağmur hendekleri yapılması

Dere kenarı restorasyonu ve yeşil yüzey kaplamaları oluşturulması 
c.Tekil yeşil altyapı elemanları

Biyokömür üretimi ve kullanımı

Çeşitli tozlaştırıcı ünitelerin uygulanması

Yeşil çitlerin uygulanması

Yeşil örtücü gölgelikler ve soğuk kaldırım uygulamaları

Eğitim amaçlı, iklim duyarlı sera alanları yapılması

d.Teknik olmayan müdahaleler

Halkın düzenlenecek çeşitli eğitim faaliyetlerine katılımı

Halkın birlikte-tasarım faaliyetlerine katılımının desteklenmesi

Bu çözümlerin yardımıyla kent bütününde rekreaktif amaçlı yeşil alan miktarı, türü ve biyoçeşitlilik artacaktır. Yürüyüş ve bisiklet hatları yapılacaktır. Kentin hava kalitesinde artış, karbon salınımında ve 1sı adası etkilerinde azalma yaşanacaktır. Sürdürülebilir su altyapıları ile su tasarrufu sağlanacaktır. Altyapı uygulamaları ile su taşkınları ve sel felaketlerinde azalma beklenirken, iklim değişikliği konusunda halkın daha fazla bilinçlendirilmesi sağlanacaktır. Bunların yanı sıra, yerel tarımsal üretimin desteklenmesi ve istihdam olanaklarının artması hedeflenmektedir. Proje kapsamında günümüze kadar gerçekleştirilen uygulamalar Çiğli ilçesinde Sasalı doğal yaşam parkında birçok uygulama ve yine Çiğli'de Biyo-Bulvar tasarımı ve kentsel tarım alanları ile biyoyakıt üretim birimi, Karşıyaka ilçesinde Girne Bulvarı üzerindeki parkletler ve Mavişehir semti Peynircioğlu deresi sürdürülebilir kıyı düzenlemeleri gibi farklı çeşitliliktedir.

\section{Yöntem ve Bulgular}

$\mathrm{Bu}$ çalışmanın ana argümanı, biyofilik kent tasarımı esaslarından kabul edilen, kent bütünde makro ve üst ölçek planlama ve dönüşüm müdahaleleri yerine mikro-müdahaleler ile yerel ölçekten başlayan çözümlerin keşfedilerek ön plana çıkartılmasıdır. Yerelde yapılan müdahaleler ile kent bütününde entegrasyonun artacağı ve ulaşım bağlantılarının kuvvetleneceği öngörülmektedir. Yerel ölçek olarak mahalle ve konut çevresi ölçeğine odaklanan çalışma, mahalle parklarının erişilebilirliği ve olası park bağlayıcı ağların keşfini nokta tabanlı erişilebilirlik yaklaşımı ile ele almıştır. $\mathrm{Bu}$ analitik mekansal yaklaşımın operasyonel hale gelmesi veri temelli tasarım şeklinde kurgulanmıştır. Mevcut mekansal veriler kullanılarak CBS veritabanı oluşturulmuş, CBS yazılımı olarak ArcMap 10.5 ve network ağ analizleri kullanılmıştır. Çalışma alanında bulunan mevcut park alanlarının erişilebilirliği, network (gerçek mesafe) tabanlı çalışan servis analizi kullanılarak hesaplanmıştır. Park alanlarının maksimum 500m içindeki erişim hatları hesaplanmıştır ve böylece alandaki konut birimlerinin (en kısa) hangi mesafede bir park alanına eriştiği ortaya konulmuştur. Devamında, alandaki mevcut yapılaşmamış alanların park alanı olması durumunda park alanı erişim mesafesi azalan konut birimleri belirlenip, yeni mekânsal düzende tüm park alanları arası olası yürüme aksları tespit edilmiştir. İkinci kısımda ise yine network tabanlı çalışan konum-tahsis analizi kullanılmıştır.

Servis alanı analizi, herhangi bir hizmet alanının, belirli bir eşik mesafe değeri içerisinde, mevcut ulaşım ağı üzerinden servis verdiği alanları tanımlayarak, o alandan ulaşılabilen tüm sokakları gösterir (Oh ve Jeong, 2007). Çalışma alanındaki mevcut park alanları, hizmet alanı olarak ele alınmıştır ve 500m mesafe içerisinde mevcut ulaşım ağı üzerinden, bu park alanlarının servis verdiği alan ve servis verdiği ulaşım hatları hesaplanmıştır (Şekil 2). Analiz sonuç haritasında görüldüğü üzere, 18 adet park alanının tamamı, 200m (koyu kırmızı yol hatları) içerisindeki konutlara hizmet vermektedir. Bazı konut alanları ise 400m (turuncu yol hatları) içerisinde bir park alanına ulaşabilmektedir. Özetle, park alanlarının yoğunlaştığı alanlarda (alanın kuzeyi) konut alanlarının ortalama $300 \mathrm{~m}$ içerisinde bir park alanına eriştiği görülmektedir. Fakat, konut birimleri ve ulaşım ağının su öğesi olan Meles Deresi ile ilişki kurmadığı ve Meles Deresi üzerinden ulaşımın tek bir hat üzerinden yapılabildiği gözükmektedir. Meles Deresi boyunca, mevzuatın da izin vermediği mesafede yerleşmiş konut ve sanayi birimleri, bu dere aksının bir kamusal bağlantı öğesi olarak kullanılmasını engellemiştir. 


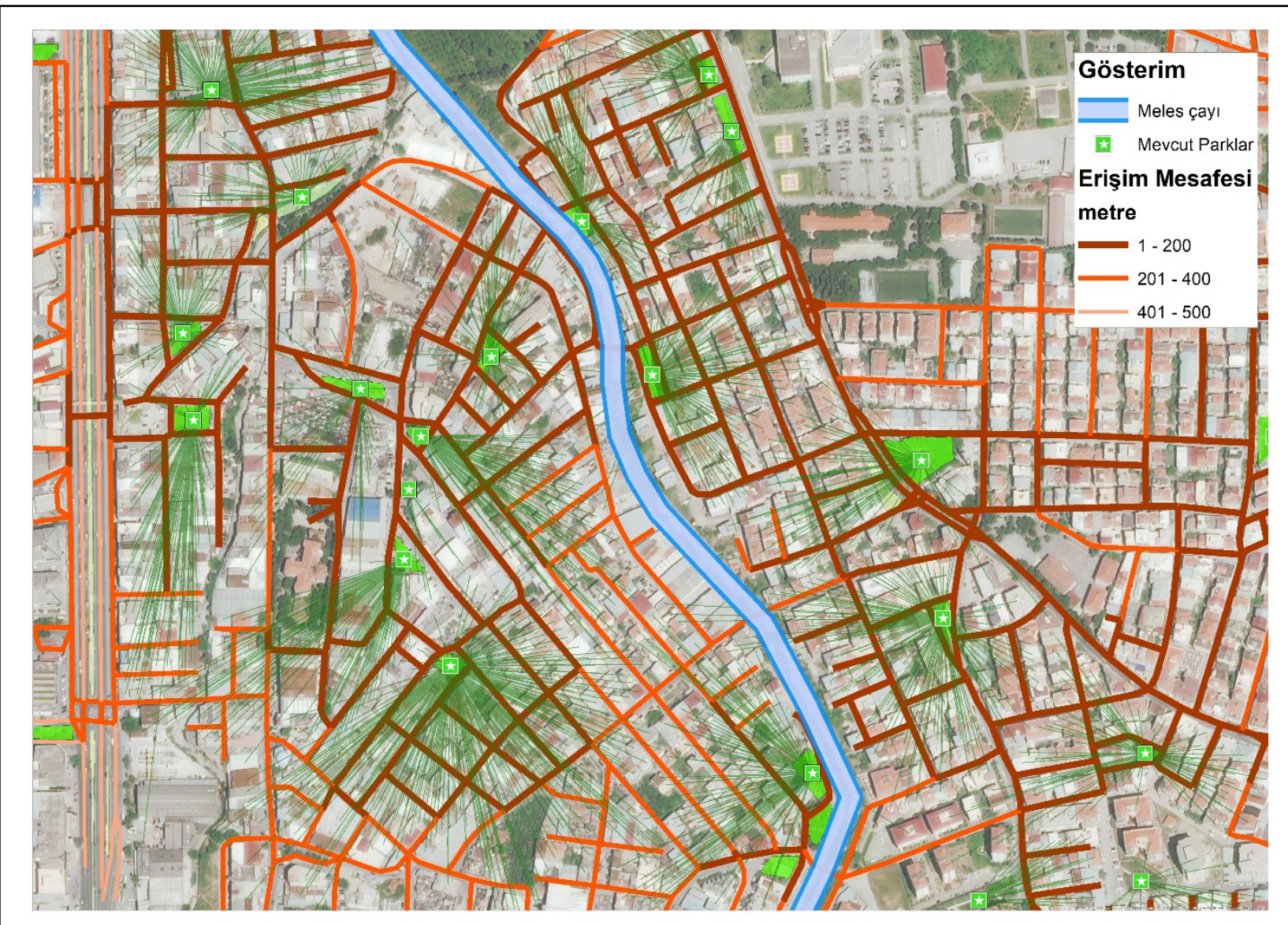

Şekil 2: Mevcut Parkların Servis Verdiği Ulaşım Hatları

Çalışmanın devamında, servis alanı analizi yardımıyla mevcut park erişim durumunu değerlendirdikten sonra, alandaki yapılaşmamış alanların park alanı olarak değerlendirilmesi durumunda, yeni erişim mesafeleri hesaplanmış ve bu yeni park alanları hesaba katıldığında, olası park bağlayıcı aks olarak çalışabilecek ana yaya ulaşım hatları tespit edilmiştir. Çalışmanın bu kısmında, konum-tahsis analizi kullanılmışıı. Bu analiz yardımı ile öneri park alanlarından 500m içerisinde erişimi görece yüksek olanların seçimi yapılmıştır ve hangi konut biriminin hangi park alanından servis alabileceği görsel olarak betimlenmiştir. Konum-tahsis analizi, bir mekânsal noktalar kümesi içerisinden, istenen kriterleri sağlayan tüm noktaları seçmektedir. Bu seçimi yaparken belirli bir formülasyonu takip eder. Seçilen her bir noktanın konumunu ifade eden formül aşağıdaki gibidir, bu formülde ' $a$ ' eşik mesafe değeri içinde olup olmama durumuna göre ikili bir değeri $(0,1)$, ' $w$ ' mekansal ağırlık kriterini (alan büyüklüğü, kişi kapasitesi vb.) ve 'd' mesafe kriterini temsil etmektedir (Rushton, 2001; Yeh ve Chow, 1996):

$$
\mathrm{z}=\sum_{i=1}^{n} \sum_{j=1}^{m} a_{i j} w_{i} d_{i j}
$$

Bu çalışmada, konum-tahsis analizini gerçekleştirmek için temel kriter yürüme mesafesinin belirlenmesidir. Öneri park alanları arasından seçim yapılırken temel kriter, park alanlarının hem konutlara hem de birbirlerine olan yürüme mesafesinin en az olması öncellenerek, en çok 500m olması temel kriter olarak belirlenmiştir. Alanda tespit edilen mevcut yapılaşmamış alanlardan dokuz adedi (öneri park) 500m içerisinde ulaşılabilir olarak hesaplamıştır (Şekil 3) Bu öneri alanların parka dönüştürülmesi durumunda (öneri ve mevcut) alandaki tüm parklara olan yürüme mesafesi azalmıştır. Park bağlayıcı ağların tespiti içinse, alandaki mevcut olası nüfus çekim alanlarının (okul, cami vb.) konumu dikkate alınmıştır. Meles deresinin kuzey-güney hattında yeşil omurga gibi çalışmasına katkıda bulunacak ve doğu-batı 
hattında çalışacak park bağlayıcı ağlar önerilmiştir. Park alanları ile alandaki cami, okul, kilise gibi diğer çekim noktalarını birbirine bağlayan yaya odaklı akslar önerilmiştir.

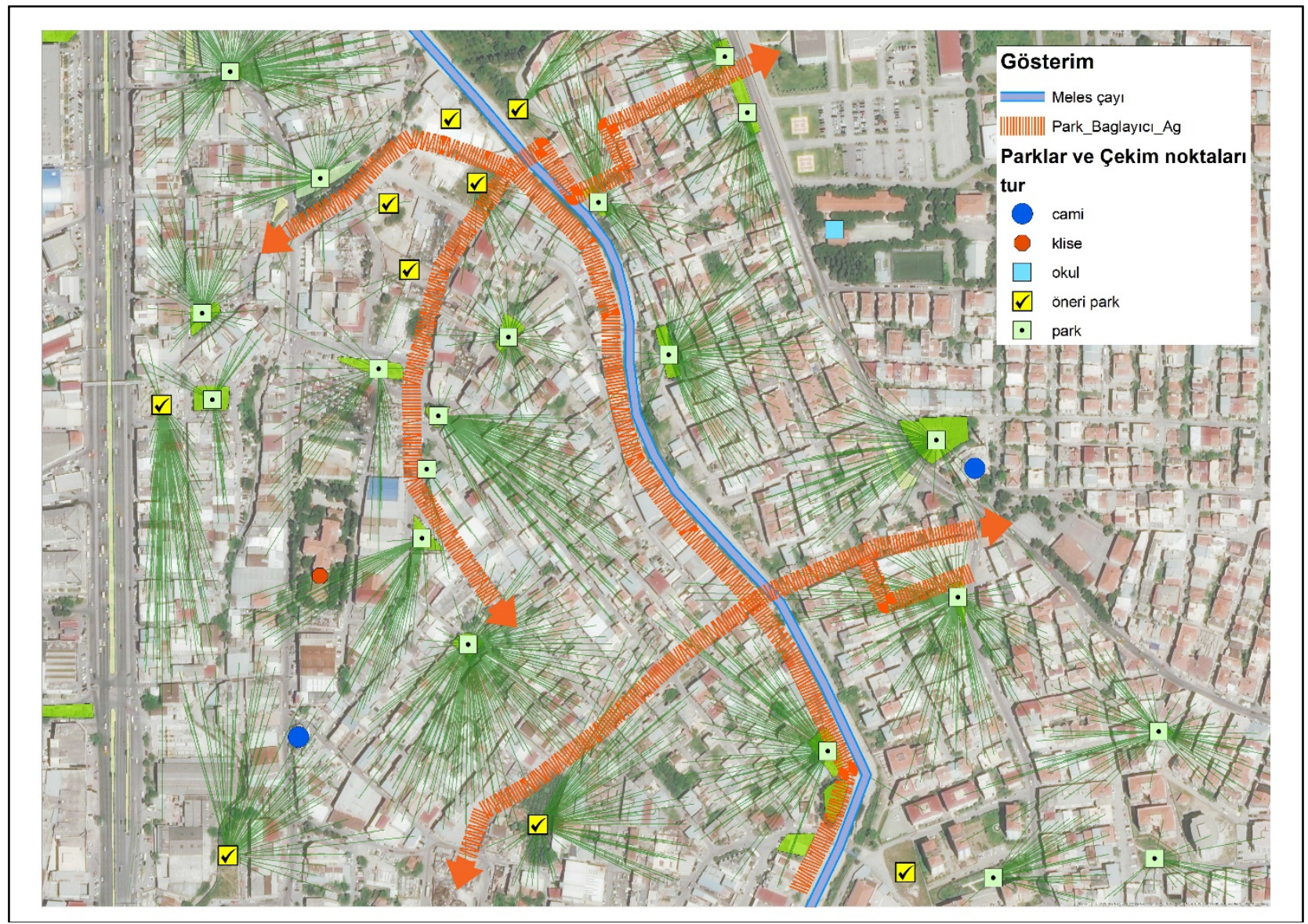

Şekil 3:Öneri parklar ve park bağlayıcı ağlar

$\mathrm{Bu}$ öneri, sokakların sadece hareket alanları olarak değil, yaşanan mekanlar olarak yeniden ele alınması ve kullanıcıların parklarda geçirdikleri zamanı sokağa da yayma amacına da hizmet etmektedir. Öneri yaya aksları, yaya yoğunluğunun görece fazla olacağı varsayılan, kamusal çekim noktalarının yoğunlukta olduğu sokaklar öncellenerek seçilmiştir. Kuzeydeki aks, öneri park alanları ile park yoğunluğu artan iki sokaktan başlayıp, derenin karşısındaki okul alanına doğru uzanmaktadır. Güneydeki aks ise öneri park alanında başlayıp, diğer parkların erişim mesafesinde devam ederek derenin karşısındaki cami ve parkın birlikte bulunduğu alana uzanmaktadır (Şekil 3).

\section{SONUÇ:}

Doğanın ve doğal sistemlerin yapılı çevre ile başarılı entegrasyonu, kentleri insan ve tüm canlılar için sağlıklı bir yaşam alanı haline getirebilir. Biyofilik bir şehir, doğa ve doğal sistemler tarafından sağlanan birçok araçsal ve ekonomik değerin yanı sıra, doğayla günlük temas ortamları sunar. Biyofilik kentsel planlamada ana tema, insanların "evrenin sahibi" değil, ekolojik sistemlerde diğer canlılar ile aynı yaşam alanını paylaştığı görüşüdür (Tabb, 2021). İdeal olarak, biyofilik kentleşme yaklaşımında birden fazla coğrafi ölçekte eylem planlamak gerekmektedir. Doğaya erişim, birçok farklı yolla ve çeşitli doğal özelliklere erişim yoluyla gerçekleşebilir. Bu özelliklerin türü ve kapsamı, yapı ölçeğinden kent ölçeğine çoklu ölçeklendirme yaklaşımıyla mekansal ölçeğe bağlı olarak değişecektir. Bu da geniş bir biyofilik tasarım paletine sahip olan kentsel alanlar ile sonuçlanır (Beatley, 2009). 
Gelişmekte olan bir yaklaşım olarak biyofilik kentleşme, doğayla doğuştan gelen ilişkinin teorik önermelerinden yararlanarak, kentsel alanların bütünsel sağlık ve refah faydalarını geliştirmek için tasarım öğeleri ve planlama yaklaşımları önerir. Bunlar, plancılara ve tasarımcılara, mekansal/kentsel sorunları çözmede ve karar üretme mekanizmalarında yardımcı olabilecektir. Biyofilik kentleşmenin gündeme girmesiyle; kentsel alanların çeşitli ölçeklerinde doğanın özelliklerinin kullanımının teşviki, çoklu fayda sağlayan doğal tekniklerin kullanılması, tasarım ve politika geliştirmede entegre, çok disiplinli ve çok partnerli süreçlerin kullanılması ve sağladığı çoklu değerlerin tanınması sayesinde kentsel yeşillendirme için finansman sağlanabilmesi gibi gelişmeler meydana gelmiştir (Reeve vd., 2015).

Biyofilik kentleşmenin ayrılmaz bir parçası, alt ölçeklerde doğa odaklı mekansal karar ve müdahalelerdir. Alt ölçek olarak mahallelerde ve çevresinde yeterli park ve doğal alan tasarlanması esastır. Bu amaçla, kentlerde parkların belirli mesafe ölçüleri içinde veya kişi başına hektar/dönüm olarak ifade edilen hedefler veya kriterler belirlenmiştir. Her mahalle, doğayı yeniden kentsel alan ile buluşturmak ve kentlerin doğallaştırılması için elverişli kentsel mekânlardır. $\mathrm{Bu}$, yapı ve konut birimleri dışındaki alanları, doğal yaşam alanları olarak yeniden tasavvur ederek ve elverişli alanlarda yaya odaklı ulaşım aksları tasarlayarak başarılabilir. $\mathrm{Bu}$ 'yeşil mahalleler', otomobillerin varlığını en aza indirerek, yürüyüş ve diğer açık hava etkinlikleri için güvenli alanların oluşmasını teşvik etmeyi amaçlar. Bu amaçla, yeşil mahallelerde, kaldırımlarla bağlantılı sokaklar, araçsız veya araba sınırlı alanlar ve mahalleyi daha büyük yeşil alan ve doğa ağlarına bağlayan yeşil yollar tasarlanabilir. Fakat öte yandan, mevcut yoğun kentsel dokularda, yeni parklar için yer tahsis etmek ve biyofilik hedeflerle uyumlu olmasını sağlamak temel bir planlama sorunudur. Bu bağlamda, kentsel alanlardaki mevcut doğal ve yapay öğelerin sahip olduğu potansiyelin kullanılması esastır.

$\mathrm{Bu}$ çalışma, biyofilik kentleşme düşüncesinin nasıl pratiğe dönüştürülebileceğini mahalle ölçeğinde park alanları üzerinden ele almaktadır. Mahalle alt ölçeğinde, mahalle parkları ve yaya odaklı akslara kadar biyofilik tasarımın, tüm mahalle sakinlerinin sosyal, duygusal ve fiziksel refahına nasıl katkıda bulunabileceğini ele almaktadır. Çalışma, mahalle ölçeğinde yeni park alanları ile erişimi artırmayı ve parklar arası mekansal ilişkiyi iyileştirmeyi hedeflemektedir. Mahalle ölçeğindeki ufak parkların entegrasyonu ile kent ölçeğinde entegre bir yeşil altyapı oluşturulabileceğini varsaymaktadır. Entegre ve erişilebilir yeşil altyapı ile mekânsal adaletin de artması hedeflenmektedir. Çalışma alanı olarak, İzmir kenti, kuzey alt bölgesinde uzanan Meles Deresinin ekolojik omurga olma potansiyeli esas alınarak, dere hattı üzerindeki yoğun bir konut dokusu seçilmiştir. Bu konut alanında mevcut parkların erişilebilirliği hesaplanmış ve yürüyerek erişimin artırılması amacı ile yapılaşmamış alanlardan erişilebilirliği en yüksek alanlar yeni park alanı olarak önerilmiştir. Alanda 18 adet park bulunmaktadır ve alanın ortasından Meles deresi geçmektedir. Mevcut durumda Meles deresi boyunca yeşil alanların ve park bağlayıcı ağların eksikliği dikkat çekmektedir. Yeşil alan erişimini artırmak için dokuz adet yeni park alanı ve Meles deresini bağdaştırıcı bir unsur olarak canlandırmak için yaya odaklı akslar önerilmiştir. Bunlar, park alanları ve su öğesini de kapsayan yaya öncelikli akslar olarak önerilmiştir.

$\mathrm{Bu}$ örnek alan uygulaması, Biyofilik kentleşme için mahalle ölçeğinin ve erişilebilirliğin önemini tekrar vurgu yapmıştır. Uygulama, mahalle ölçeğindeki erişilebilir ve entegre parkların kent ölçeğindeki bir yeşil altyapının yapıtaşları olacağını göstermeyi hedeflemiştir. Uygulamanın odak noktasında bulunan Meles Deresi; park alanları ve diğer kamusal çekim noktaları arasındaki bağlantıyı yaya odaklı akslar ile sağlayan bir yeşil altyapının omurgası olarak konumlandırılmıştır. Öte yandan uygulama için seçilen yeşil alanların kamusal parklar olması, yapılan müdahalenin daha çok bireye asgari maliyet ile ulaşabilir olmasını sağlamaktadır. Bu yönüyle de uygulama, hem yürüyerek erişilebilirlik açısından mekansal adalete hem de mahalle sakinlerinin sosyal, duygusal ve fiziksel refahı açısından kentsel yaşam kalitesine olumlu katkı sağlayacaktır. Bilindiği üzere Meles deresi ve kentteki diğer dereler, mekansal birleştirici bir öğe olarak, kendisine bağlanan tüm yeşil alanlar ile kentsel ölçekte bir yeşil altyapı olma potansiyeline sahiptir. İzmir Büyükşehir Belediyesinin, 'GreenUp' kapsamında kentin kuzeyinde yaptığı uygulamalar ve Meles Deresi için açtığı ulusal fikir yarışması da bu potansiyeli hayata geçirme çabalarıdır.

\section{Etik Standart ile Uyumluluk}

Çıkar Çatışması: Yazar herhangi bir çıkar çatışmasının olmadığını beyan eder.

Etik Kurul İzni: Bu çalışma için etik kurul iznine gerek yoktur. 


\section{KAYNAKÇA:}

Apparicio, P., Abdelmajid, M., Riva, M., \& Shearmur, R. (2008). Comparing alternative approaches to measuring the geographical accessibility of urban health services: Distance types and aggregation-error issues. International Journal of Health Geographics, 7(1), 7. https://doi.org/10.1186/1476-072X-7-7

Barton, H.,\& Grant, M. (2010). Shaping neighbourhoods : For local health and global sustainability. London; New York: Routledge, Taylor \& Francis Group.

Beatley, T. (2009). Biophilic Urbanism: Inviting Nature Back to Our Communities and Into Our Lives. William \& Mary Environmental Law and Policy Review, 34(1), 209-238.

Beatley, T., \& Newman, P. (2013). Biophilic Cities Are Sustainable, Resilient Cities. Sustainability (Switzerland), 5(8), 3328-3345.

Day, R. (2008). Local environments and older people's health: Dimensions from a comparative qualitative study in Scotland. Health and Place, 14(2), 299-312.

Ekkel, E. D., \& de Vries, S. (2017). Nearby green space and human health: Evaluating accessibility metrics. Landscape and Urban Planning. 157, 214-220, https://doi.org/10.1016/j.landurbplan.2016.06.008

European Union's Horizon 2020 Research and Innovation Programme. (2021). https://www.urbangreenup.eu/.

İzmir Büyükşehir Belediyesi. (2021). Kentsel ve Ekolojik Omurga Olarak Meles Çayı Ulusal Kentsel Tasarım Fikir Projesi Yarışması. Ege Mimarlık, 110(2), 6-12.

Kara, B., Tuncay, H. E., \& Deniz, B. (2011). Investigating recreational qualities of the parks in Aydin. Procedia Social and Behavioral Sciences, 19, 158-164.

Kearns, A., \& Parkinson, M. (2001). The Significance of Neighbourhood. Urban Studies, 38(12), 2103-2110.

Kwan. M. P. (2010). Space-Time and Integral Measures of Individual Accessibility: A Comparative Analysis Using a Point-based Framework. Geographical Analysis, 30(3), 191-216. https://doi.org/10.1111/j.1538-4632.1998.tb00396.x

Kwan, M. P. (1999). Gender and individual access to urban opportunities: A study using space-time measures. Professional Geographer. 51(2), 210-227, https://doi.org/10.1111/0033-0124.00158

Kwan, M. P. (2002). Feminist visualization: Re-envisioning GIS as a method in feminist geographic research. Annals of the Association of American Geographers. 92(4), 645-661, https://doi.org/10.1111/1467-8306.00309

Matan, A., \& Newman, P. (2015). Green Urbanism in the Indian Ocean Region. Journal of the Indian Ocean Region, $11(1), 60-73$.

Moser, G., Ratiu, E., \& Fleury-Bahi, G. (2002). Appropriation and Interpersonal Relationships: From Dwelling to City Through the Neighborhood. Environment and Behavior, 34(1), 122-136.

Neutens, T., Schwanen, T., Witlox, F., \& De Maeyer, P. (2010). Equity of Urban Service Delivery: A Comparison of Different Accessibility Measures. Environment and Planning A: Economy and Space, 42(7), 1613-1635. https://doi.org/10.1068/a4230

Newman, P. (2014). Biophilic urbanism: a case study on Singapore. Australian Planner, 51(1), 47-65.

Oh, K., \& Jeong, S. (2007). Assessing the spatial distribution of urban parks using GIS. Landscape and Urban Planning, 82(1-2), 25-32. https://doi.org/10.1016/j.landurbplan.2007.01.014 
Özden, M. A. (2019). Yaşanabilir Kentler İçin Yeni Bir Yaklaşım Olarak ‘Biyofilik Tasarım’ Teoriden Uygulamaya Bir Değerlendirme. Şehir ve Şehir Yönetimi, 597-621.

Reeve, A., Desha, C., Hargreaves, D., \& Hargroves, K. C. (2015). Biophilic urbanism: contributions to holistic urban greening for urban renewal. Smart and Sustainable Built Environment, 4(2), 215-233.

Rigolon, A. (2016). A complex landscape of inequity in access to urban parks: A literature review. Landscape and Urban Planning. 153, 160-169, https://doi.org/10.1016/j.landurbplan.2016.05.017

Rushton, G. (2001). Spatial decision support systems. In Smelser, E.-i.-C. N. J. and Baltes, P. B., editors, International Encyclopedia of the Social \& Behavioral Sciences, pages 14785-14788. Pergamon, Oxford.

Stafford, L., \& Baldwin, C. (2018). Planning Walkable Neighborhoods: Are We Overlooking Diversity in Abilities and Ages? Journal of Planning Literature. 33(1):17-30, https://doi.org/10.1177/0885412217704649

Swyngedouw, E., \& Heynen, N. C. (2003). Urban political ecology, justice and the politics of scale. Antipode. 35(5), 898 - 918, https://doi.org/10.1111/j.1467-8330.2003.00364.x

Tabb, P. J. (2021). Biophilic Urbanism Designing Resilient Communities for the Future. Routledge, Taylor \& Francis Group.

Talen, \& Anselin, L. (1998). Assessing spatial equity: An evaluation of measures of accessibility to public playgrounds. Environment and Planning A. 30(4), 595-613, https://doi.org/10.1068/a300595

Tan, P. Y., \& Samsudin, R. (2017). Effects of spatial scale on assessment of spatial equity of urban park provision. Landscape and Urban Planning. 158, 139-154, https://doi.org/10.1016/j.landurbplan.2016.11.001

Tsou, K. W., Hung, Y. T., \& Chang, Y. L. (2005). An accessibility-based integrated measure of relative spatial equity in urban public facilities. Cities, 22(6), 424-435. https://doi.org/10.1016/j.cities.2005.07.004

Türkiye İstatistik Kurumu, 2020, https://www.tuik.gov.tr/

Williams, A. (2002). The Optimal Provision of Public Goods in a System of Local Government. Journal of Political Economy. 74(1), 18-33, https://doi.org/10.1086/259106

Yeh, A. G. O., \& Chow, M. H. (1996). An integrated GIS and location-allocation approach to public facilities planning: An example of open space planning. Computers, Environment and Urban Systems, 20(4), 339-350. https://doi.org/https://doi.org/10.1016/S0198-9715(97)00010-0 